\title{
Estudo sobre o engajamento de usuários de uma mídia social disponibilizada pelo governo
}

\section{Alternative Title: Study about users' engagement of a governmental social media}

\author{
Camila Mariane Costa Silva \\ Universidade de São Paulo \\ Av. Arlindo Béttio, 1000 \\ São Paulo - SP, Brasil \\ cmcsilva@usp.br
}

\author{
Edmir Parada Vasques Prado \\ Universidade de São Paulo \\ Av. Arlindo Béttio, 1000 \\ São Paulo - SP, Brasil \\ eprado@usp.br
}

\begin{abstract}
RESUMO
O uso de mídias sociais está se difundindo, a partir do momento em que estas possibilitam o compartilhamento de informações e a criação de comunidades virtuais e de mecanismos de interação. Perante estas características, organizações públicas têm utilizado mídias sociais para mobilizar, informar e chamar seu públicoalvo à participação social. Contudo ainda é uma preocupação se esta ferramenta é capaz de promover o engajamento desse público. Neste sentido, este estudo tem o objetivo de analisar como as funcionalidades de uma mídia social, disponibilizada pelo próprio governo, influenciaram o engajamento dos usuários. Para tanto, foi realizado um estudo netnográfico em que foram observadas e analisadas as interações de uma comunidade inserida em uma plataforma disponibilizada pelo governo federal brasileiro. Por fim verificou-se que nem todos os recursos foram bem explorados pelos usuários, e ainda que os usuários tenham passado pelo processo de engajamento, sua experiência de uso não foi tão satisfatória para que mantivessem sua frequência de acessos.
\end{abstract}

\section{Palavras-Chave}

Mídia social; Governo; Engajamento do usuário; Netnografia.

\begin{abstract}
The social media use has been diffusing since they are enabling information sharing and the creation of virtual communities and interaction mechanisms. Due to its characteristics, public agencies have used social media for mobilizing, inform and call their public to take part of social participation. However, if this kind of tool is capable to promote engagement in the public, is still a matter to be worried of. Thus, this study aims to analyze how a governmental social media's functionalities influence the
\end{abstract}

Permission to make digital or hard copies of all or part of this work for personal or classroom use is granted without fee provided that copies are not made or distributed for profit or commercial advantage and that copies bear this notice and the full citation on the first page. To copy otherwise, or republish, to post on servers or to redistribute to lists, requires prior specific permission and/or a fee.

SBSI 2015, May 26-29, 2015, Goiânia, Goiás, Brazil.

Copyright SBC 2015. engagement of users. Then a netnography study was accomplished. In this study we observed and analyzed interactions from a community in a social media platform that was released by the Brazilian federal government. Finally, we verified that some of its resources were not well explored by users. Even if they got through the process of engagement, their use experience was not so satisfactory to make them keep their access frequency.

\section{Categories and Subject Descriptors}

H.1.2 [Information Systems]: User/Machine Systems - human factors, human information processing, software psychology; K.4.0 [Computers and Society]: General.

\section{General Terms}

Human Factors, Measurement, Verification.

\section{Keywords}

Social media; Government; User's engagement; Netnography.

\section{INTRODUÇÃO}

As organizações públicas, de maneira geral, vêm adotando mídias sociais para atingir o público-alvo de seus serviços. Tais organizações utilizam os diversos tipos de mídias sociais como canais de relacionamento, a fim de aumentar a transparência de informações, suportar atividades colaborativas internas e externas, e como uma forma de inovação na promoção da participação e do engajamento civil [1].

A respeito de um desses propósitos, o estudo descrito em [2] evidencia o papel das mídias sociais no engajamento de pessoas no processo democrático, visto o crescente número de acessos a estas mídias. Este processo refere-se à participação civil (política e social) do cidadão junto aos projetos de programas ou políticas públicas de instituições governamentais.

O estudo em [2] evidencia que a confiança em mídias sociais está positivamente relacionada com a participação do cidadão. Desse modo, é possível entender que essa relação se deve ao potencial estímulo ao envolvimento comunitário que as mídias sociais possuem. 
Neste sentido, com base no que é sugerido em [3] e levantado por [4], este estudo tem o objetivo de analisar como as funcionalidades de uma mídia social, disponibilizada pelo próprio governo, influenciaram o engajamento de seus usuários. $\mathrm{O}$ engajamento, neste contexto, se refere ao envolvimento dos usuários com as discussões promovidas na plataforma em questão, e não somente com a vontade de permanecer utilizandoa. Procurou-se obter lições sobre a forma de aplicação destas funcionalidades, verificando o que pode ter sido mais ou menos adequado, no contexto em que se estava inserido.

Para realizar a análise proposta, foi necessário escolher uma mídia social, oferecida pelo governo, e um de seus grupos, para compor o caso para este estudo. Assim, foi selecionada a mídia social Participa.br [18], pertencente ao governo federal brasileiro, que foi lançada em 2013. Em relação ao grupo, optouse pela comunidade Participação Social [19], por ser um dos grupos que mais recebeu contribuições em suas discussões. Ressalta-se que esta plataforma foi oferecida com o intuito de permitir que a população brasileira pudesse propor debates e participar de espaços que promovessem a construção de políticas públicas [20].

\section{REVISÃO DA LITERATURA}

Para compor a base teórica necessária à análise proposta nesta pesquisa, foram trazidos dois principais conceitos: a estruturação funcional de uma mídia social e o engajamento do usuário de um sistema de informação. Ambos são descritos nas subseções seguintes.

\subsection{Blocos Funcionais de Mídias Sociais}

Visando a melhoria do entendimento da estrutura funcional de uma mídia social, o estudo realizado em [4] apresentou um framework com sete blocos funcionais construtores desta ferramenta. Utilizados juntos e/ou separados, estes blocos têm o intuito de ajudar gestores de organizações a compreenderem as funcionalidades componentes de uma mídia social e o seu público. Além disso, a entenderem o que é necessário para este público se engaje a partir do uso dessa ferramenta. A Figura 1 ilustra o diagrama dos sete blocos funcionais.

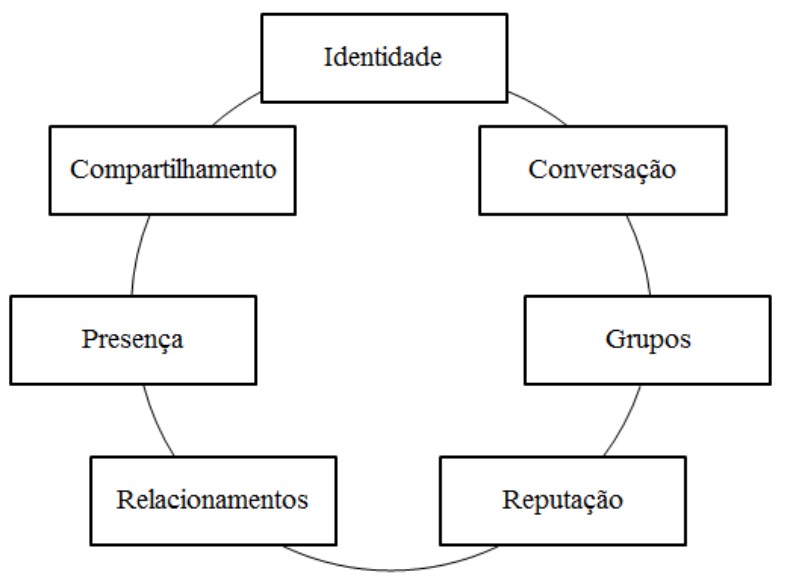

Figura 1. Os sete blocos funcionais [4].

Assim, cada um dos blocos funcionais pode ser descrito [4]:

- Identidade: um conjunto de recursos para a construção de um perfil para o usuário, no qual são divulgadas informações pessoais, que tenham sido previamente cadastradas.

- Conversação: conjunto de recursos para comunicação entre os usuários seja no formato de envio de mensagens, quanto de postagem de conteúdos. A conversação pode se dar entre múltiplos usuários ou apenas com um.

- Grupos: um conjunto de recursos que possibilitem a criação de grupos (ou comunidades) pelos usuários. Também se refere a recursos que permitem que os usuários se incluam/excluam nestes grupos.

- Reputação: conjunto de recursos que permitam que os usuários identifiquem a atribuam reputação a conteúdos compartilhados ou, até mesmo, a outros usuários.

- Relacionamentos: conjunto de recursos de inclusão de amigos a sua rede de contatos, sejam estes externos à plataforma (na forma de convites para se cadastrarem) ou já internos.

- Presença: um conjunto de recursos que possibilitam que o usuário possa mencionar onde está. Também se refere a recursos que permitem que outros usuários percebam quando outros estão acessando a plataforma naquele momento.

- Compartilhamento: conjunto de recursos para viabilizar publicação de diversos tipos de conteúdo em alguns locais, pelos usuários. Um dos exemplos de local para compartilhamento é o mural do perfil pessoal.

Durante a realização desta pesquisa, os recursos da plataforma selecionada foram identificados de acordo com cada um destes blocos funcionais.

\subsection{Processo de Engajamento do Usuário}

No intuito de avaliar se um usuário esteve ou não engajado, enquanto utilizava uma mídia social, é necessário que antes se compreenda como o engajamento ocorre nesta relação. Nesse sentido, o estudo [6] levantou diversas teorias que poderiam estar associadas ao engajamento de indivíduos.

A partir da escolha e compatibilização de atributos dessas teorias, foi desenvolvido um framework que descreve as fases do engajamento do usuário. Assim, foi compreendido que tais fases são consecutivas dentro de um processo que se inicia com o ponto de engajamento, passa pelo período de engajamento e se encerra no desengajamento. $\mathrm{O}$ retorno ao envolvimento pode acontecer no reengajamento ou ainda pode-se chegar, simplesmente, ao não engajamento [6].

O não engajamento pode ocorrer pelo fato do usuário não apreciar a experiência de interação com um sistema de informação em detrimento da experiência social [6]. Pode-se afirmar que há duas principais barreiras para o não desenvolvimento do engajamento: o conteúdo disponibilizado não atrai a atenção, curiosidade ou interesse de seu público-alvo; ou pouca usabilidade na ferramenta [6].

Cada uma das fases, por sua vez, contém atributos que as influenciam. Na primeira, ponto de engajamento, estes são: estética; inovação/novidade; interesse; motivação; e objetivo experimental ou específico - note-se que se tratam dos mesmos atributos para a fase de reengajamento. Na segunda, referente ao período de engajamento, são: estética e apelo sensorial; atenção; 
consciência; controle; interatividade; inovação/novidade; desafio; feedback; interesse; e efeito positivo. Por fim, na fase de desengajamento, são: usabilidade; desafio; efeito positivo; efeito negativo; tempo percebido; e interrupções [6]. Os atributos dessas fases podem ser descritos da seguinte forma [6]:

- Atenção: concentração mental estimulada pela tarefa que ela está executando. Esta pode ser empregada para navegar na plataforma, postar comentários e/ou compartilhar conteúdo etc.

- Consciência: conhecimento da situação vivenciada, interesse ou preocupação fundamentada em uma situação em particular ou objetivo.

- Controle: domínio sobre as atividades que estiver realizando.

- Desafio: quantidade/intensidade de esforço empregado pelos usuários para realizarem as atividades disponibilizadas no sistema.

- Efeito negativo: impressões ruins a partir da execução das atividades no sistema.

- Efeito positivo: boas impressões a partir da execução das atividades no sistema.

- Estética [e apelo sensorial]: funcionalidades e recursos da plataforma são agradáveis ao olhar, pois possuem beleza. $\mathrm{O}$ apelo sensorial refere-se à vontade de participar das atividades devido às sensações causadas pela a interface do sistema.

- Feedback: informação comunicada aos usuários a partir das ações realizadas ou de resultados obtidos. Pode se referir à informação emitida por administradores do sistema.

- Inovação/Novidade: é a tendência de buscar elementos novos, interessantes ou incomuns no ambiente. Mudanças inesperadas também se aplicam a este atributo.

- Interatividade: capacidade oferecida aos usuários da plataforma em se comunicarem e trocarem conteúdos de maneira dinâmica.

- Interesse: importância ou valor pessoal atribuído às atividades disponíveis no sistema.

- Interrupções: provocados por fatores externos como alerta programado, um telefonema ou uma presença física no mesmo ambiente que o usuário.

- Motivação: razões para uso do sistema, que podem partir da influência de outras pessoas, de divulgações, de curiosidade ou de vontade.

- Objetivo (experiencial ou específico): satisfação de um propósito específico, ou satisfação da experimentação dos mecanismos da plataforma.

- Tempo percebido: percepção de que o tempo empenhado nas atividades foi excessivo, assim que se toma consciência de que ele passou muito mais do que se esperava.

- Usabilidade: facilidade em reconhecer as funcionalidades disponibilizadas no sistema e em utilizá-las.
Cada um desses atributos foi categorizado em linhas de experiência, tomando por base o trabalho de [7]. Estas linhas são: Composicional, que se refere à experiência com os dados e conteúdos oferecidos relacionando o processo de engajamento como um todo; Espaço Temporal que está relacionada ao tempo percebido sobre a interação com o sistema, com estados internos do usuário e com o ambiente externo; Emocional que se refere à experiência afetiva, ao se interagir com o sistema, e com a motivação em continuar utilizando-o; e Sensorial, que se refere à experiência promovida a partir de elementos audiovisuais e estéticos [6] [7].

\section{MÉTODO DE PESQUISA}

Este estudo tem um enfoque qualitativo, cujo objetivo é traduzir e expressar o sentido dos fenômenos do mundo social [8]. Podese considerar que se trata de uma pesquisa exploratória, pois seu intuito é analisar um fenômeno de maneira a buscar perspectivas e percepções a partir de dados empíricos, ainda não analisados da maneira proposta [9].

Foi escolhida a netnografia como estratégia de pesquisa [10] que foi aplicada a um único caso. Esta pode ser considerada a abordagem ideal para estudo de mídias sociais, se o estudo busca considerar as relações entre as afirmações inseridas nestas ferramentas em diversos contextos e aplicações [11].

A netnografia advém da etnografia e de seus conceitos de imersão na comunidade em que se estuda, considerando as relações entre os participantes e seus objetivos, para a realização de induções [8] [11]. Reforça-se que o pesquisador, neste tipo de estratégia, torna-se também um instrumento de pesquisa e, assim, deixa a sua visão pessoal sobre as reflexões obtidas.

Desse modo, foram consideradas as fases da netnografia, na realização deste estudo: planejamento, entrada (entreè), coleta de dados, análise e interpretação, ética e apresentação dos resultados. A Figura 2 ilustra as fases desta estratégia de pesquisa.

A fase do planejamento se refere à organização prévia dos passos a serem seguidos ao longo do estudo, incluindo como os dados devem ser coletados e analisados [10]. Neste sentido, foi feito um protocolo como uma forma de guia à realização da pesquisa de campo.

A fase de entrada (entreè) se refere à forma como o pesquisador se insere na comunidade escolhida [10]. Neste caso, foi criado um perfil na plataforma que foi atrelado ao grupo de interesse. Como foi assumida uma postura maior de observação, não foi necessário intervir nas discussões e atividades.

A fase de coleta de dados foi realizada em 2014 entre os meses de maio e dezembro, mesmo período em que foram realizadas as observações. Basicamente foram coletadas as postagens feitas, pelos usuários participantes da comunidade, em três discussões. Assim, obteve-se 174 comentários para a análise, que se refere ao total de interações encontradas. Esta fase também compreendeu a coleta de dados para triangulação.

Para a triangulação dos dados, foram realizadas entrevistas com doze participantes das discussões da comunidade selecionada, e consultas a documentos institucionais e notícias. Ambos foram realizados no mesmo período em que a comunidade era observada e os comentários coletados. As entrevistas, 
especificamente, foram realizadas nos meses de agosto e setembro de 2014.

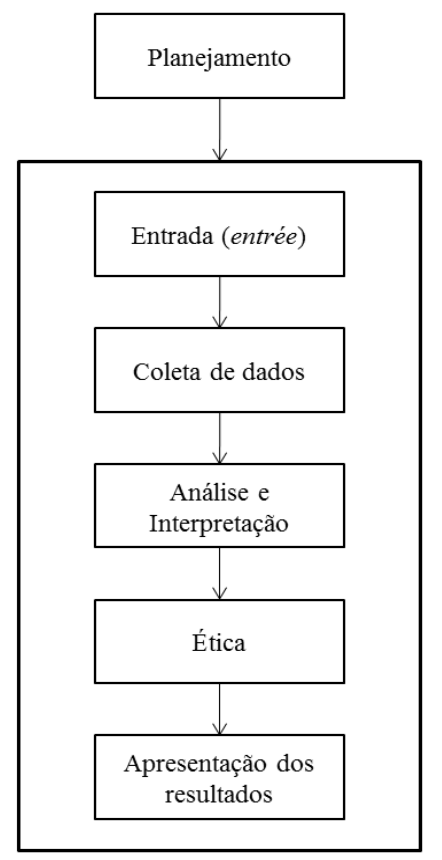

Figura 2. Fases da netnografia [11].

$\mathrm{Na}$ fase de análise e intepretação dos dados foi realizada a categorização dos comentários coletados, de modo a facilitar o entendimento sobre seus conteúdos e a intensidade das discussões. O objetivo era verificar de que maneira as pessoas estavam engajadas, considerando os dias e horários das postagens, além da forma como se expressavam através de suas colocações. As entrevistas e documentos foram utilizados nesta fase de modo a complementar as percepções obtidas nas interações e como uma forma de confirmação ou refutação destas, dando maior confiabilidade às interpretações.

A fase da ética, na verdade, tem relação com as demais fases por se tratar da maneira como a observação da comunidade será realizada, com o intuito de evitar o uso indevido de informações captadas durante a pesquisa [10]. Assim, tomou-se a precaução de solicitar autorização aos administradores da plataforma selecionada, para acompanhamento e coleta de dados postados pelos usuários. Também foi verificada a política de uso de divulgação dos dados. Em ambos os casos houve abertura para a execução deste estudo.

Finalmente, a fase de apresentação dos resultados se refere à divulgação do que foi obtido na pesquisa [10]. Desse modo, os resultados foram disponibilizados aos administradores do portal que poderiam divulga-los da maneira mais adequada para a comunidade estudada.

\section{DISCUSSÃO DOS RESULTADOS}

Das três discussões analisadas, que foram realizadas na comunidade Participação Social, duas ocorreram entre os meses de setembro e dezembro de 2013, enquanto a terceira ocorrera em junho de 2014. As duas primeiras foram consultas dos textos que dariam origem ao Decreto 8.243 de 23 de maio de 2014 [12] e ao termo de adesão ao Compromisso Nacional pela
Participação Social [13]. A terceira discussão acompanhou a realização de uma videoconferência, cuja pauta era a repercussão da Política Nacional pela Participação Social que era criada pelo decreto citado.

Outra característica importante nesta e em outras comunidades do Participa.br, é que os usuários podem participar de quaisquer atividades desses grupos, sem a necessidade de se tornarem membros. No entanto, um dos objetivos desta plataforma é formar estas comunidades que, por sua vez, poderiam se manter e se desenvolver neste ambiente.

A análise sobre os resultados é apresentada pelas fases do processo de engajamento do usuário. Em cada uma delas se remete aos recursos da plataforma de acordo com os blocos funcionais de mídias sociais. Reforça-se que as funcionalidades são aplicáveis a toda a plataforma, mas as percepções sobre as fases são dos usuários-participantes de apenas uma comunidade.

\subsection{Ponto de Engajamento \& Reengajamento}

Em relação ao ponto de engajamento pelo contato com a plataforma, um potencial usuário possui três principais formas de conhecer o que ela dispõe em conteúdos e atividades: por meio da navegação aberta ao público, diretamente pelo site do portal; pela navegação privada, após a realização do acesso autenticado do usuário; e conhecendo os conteúdos pelas mídias sociais externas - nas quais o portal possui perfil. Assim, podem ser destacados os blocos funcionais Identidade, Reputação e Compartilhamento; pois o usuário passaria a ter acesso primeiramente, aos recursos pertinentes a estes blocos.

Os recursos de criação de perfil e configuração, referentes ao bloco de Identidade seriam os primeiros recursos que um usuário poderia utilizar, caso solicitasse acesso a toda a plataforma. Os recursos do bloco de Reputação estariam mais ligados à atribuição de importância a determinados conteúdos e usuários. Estes indicadores já poderiam ser visualizados pelas publicações nas mídias sociais externas, que podem ser vistas como informações em destaque. Já o bloco Compartilhamento teria relação com os recursos que possibilitaram que as informações publicadas na navegação aberta da plataforma, estivessem disponíveis.

O atributo estética não pode ser avaliado pela observação das interações, no sentido de perceber o quanto ele pode ter influenciado no engajamento do usuário. Para melhor medi-lo seria necessário que parte dos usuários fosse estimulada a comparar interfaces de mídias sociais, em que uma delas possua características semelhantes à da plataforma. Note-se que, de qualquer modo, a aparência do portal é limpa, ainda que a cor de maior destaque seja o amarelo. Interfaces de mídias sociais populares, como o Facebook, Twitter e Linked In [14], exploram mais a cor azul ou cinza. De qualquer modo, a aparência estética da plataforma pode ter sido um atrativo para alguns dos novos usuários, ainda que não necessariamente como o seu principal motivador. Nesse sentido, nenhum dos entrevistados ponderou algum tipo de problema ou ressaltou algum ponto relacionado a este atributo.

O atributo inovação/novidade pode ter sido mais considerado pelos novos usuários da plataforma, por se tratar de uma das primeiras ferramentas em mídia social oferecidas pelo governo federal brasileiro - ainda que não citado pelos entrevistados. Daí parte-se para o atributo interesse, que pode ter sido despertado 
pela curiosidade em explorar esta novidade. Como alguns dos eventos promovidos na plataforma que a fizeram mais conhecida [17], o interesse em participar pode ter surgido a partir da percepção de que as discussões promovidas dentro desse ambiente poderiam ser instituídas em ações ou regulamentações oficiais. Além disso, os usuários podem ter se interessado pelos temas das comunidades assim que fizeram seus acessos, ou pela interatividade da plataforma.

Ressalta-se que a motivação pode ter sido influenciada pelos outros atributos citados anteriormente, inclusive pelo fato dos usuários se interessarem por políticas e gestão pública - como foi percebido em seus perfis. Neste sentido também se remete ao atributo objetivo específico ou experiencial. Quase todos os entrevistados afirmaram que seu principal objetivo em acessar a plataforma foi o de participar das discussões de uma ou mais comunidades com temáticas que lhes despertassem a atenção. Um possível objetivo experiencial seria o de utilizar uma plataforma de mídia social livre. Além disso, de verificar se suas contribuições eram, de fato, reconhecidas pelas organizações públicas envolvidas nas discussões.

\subsection{Período de Engajamento}

$\mathrm{O}$ período de engajamento, no caso estudado, refere-se ao momento em que o usuário está envolvido nas discussões propostas na comunidade, ou está acessando a plataforma com frequência. Nesta fase os recursos de todos os blocos funcionais possuem seu papel para manter o usuário engajado.

Entre os recursos de perfil do bloco de Identidade está a menção de categorias de interesse. Estas auxiliam os usuários a reconhecer pares, possibilitando o desenvolvimento de sua rede de contatos e de novas comunidades. Note-se que a possibilidade de fazer novos contatos depende dos recursos do bloco de Relacionamento. Os recursos referentes ao bloco Grupos servem tanto para a criação dessas comunidades, quanto para permitir que os usuários se tornem membros de outras.

Os recursos de Compartilhamento provêm meios para que usuários e administradores de comunidades postem textos, figuras, vídeos ou outros conteúdos informativos. Estes são acompanhados por outros usuários, cujo interesse em participar pode aumentar. Os recursos de Reputação, neste caso, servem para classificar tais conteúdos, de modo a identificar os mais interessantes ou polêmicos. Ainda assim, viu-se que não foram inseridos tantos recursos para este bloco, até porque é difícil instituir medidas para reputação [5].

Também não foram disponibilizados tantos recursos referentes ao bloco de Presença. É possível que um usuário mencione a sua localização, mas não há formas de reconhecer que este está acessando a plataforma naquele momento. Quando se vê que um usuário está online, podem ser disponibilizados recursos que permitem a troca de mensagens instantâneas. Assim, no sentido de recursos em Conversação, a plataforma oferece, sobretudo, a postagem de comentários em trechos de texto (quando em deliberação) ou em conteúdos de maneira geral. Note-se que este recurso foi um dos mais importantes no engajamento dos usuários dessa comunidade, pois foi por meio dele que fizeram suas contribuições nas discussões, e se mantiveram envolvidos.

A fim de verificar como se deu a atenção dos usuários, coletou-se o horário e dia em que estiveram postando comentários nas discussões da comunidade. Verificou-se que boa parte deles postou um ou dois comentários no mesmo dia e em horários próximos, enquanto uma parcela menor de usuários permaneceu mais tempo e postou mais de três comentários. Assim pode-se dizer que, mesmo sendo apenas alguns, houve usuários que estiveram concentrados no período em que postavam suas contribuições. Pelas informações nas interações, a atenção se voltara à discussão em si.

Em relação ao atributo consciência, viu-se que boa parte dos usuários sabia o que estava colocando, ainda que não utilizasse argumentos para sustenta-las. Contudo, nem todas as discussões se estenderam a partir das interações. Verificou-se também que havia muitos erros de digitação nos comentários, o que pode demonstrar certa pressa do usuário em expressar suas opiniões.

Alguns dos recursos disponibilizados nas discussões acabaram prejudicando a sensação de controle do usuário sobre os recursos, sobretudo de Conversação e Compartilhamento. Um desses recursos era o contador de comentários, usado em cada um dos trechos dos textos em deliberação, que acabava diminuindo ou aumentando a quantidade real de comentários inseridos.

Pelos comentários dos usuários e pelo depoimento dos entrevistados, a comunidade não trouxe desafios aos participantes das discussões. Não foram evidenciadas dificuldades que pudessem desestimular ou até estimulá-los a permanecerem envolvidos.

Assim, não foi possível avaliar o efeito positivo causado nos usuários-participantes, isso porque o atributo feedback exerce influência sobre ele. Quando os entrevistados foram questionados sobre este atributo, alguns demostraram contentamento com a ferramenta em si e com os debates, enquanto outros acreditam que ainda deveriam ser feitas diversas melhorias para que a plataforma atendesse melhor suas expectativas.

Em relação ao atributo feedback, viu-se que foram levantadas diversas questões entre os usuários que remetiam a entendimento de conceitos ou na forma de cobrança por atitudes. No entanto, poucas dessas questões foram respondidas, seja por outros usuários quanto por moderadores.

Após a publicação oficial do Decreto 8.243 de 23 de maio de 2014, por exemplo, não foi realizada outra comunicação com os membros da comunidade. Verificou-se que seu texto estava diferente daquele que foi deliberado, mas de um modo em que não foi possível reconhecer como as contribuições dos usuários foram agregadas a ele - as informações dos artigos estavam diferentes entre as versões.

Os atributos inovação/novidade e interesse se mantiveram semelhantes ao que foi observado na fase de ponto de engajamento \& reengajamento. Assumiu-se que o interesse em continuar, pode ter se originado da curiosidade em saber o que iria acontecer depois, após as contribuições com as consultas e com o acompanhamento da videoconferência.

Não foram encontradas evidências da influência do atributo estética [e apelo sensorial], pois os comentários não faziam qualquer menção à imagem da plataforma ou dos recursos que utilizam nas discussões. A respeito da parte específica do apelo sensorial, que remete ao engajamento pelo estímulo de outros sentidos humanos; não foram percebidos recursos ou indicadores que o fizessem. 
$\mathrm{O}$ atributo interatividade, por sua vez, pode ter desempenhado um papel importante para estimular o engajamento. Isso, pois a maior parte dos debates entre usuários ocorreu em dias distintos ainda que em dias próximos. Presumiu-se que, com as notificações sobre postagens de respostas, pode ter sido possível estimular que os usuários retornassem à plataforma para verificar o que tinha sido colocado sobre seus comentários - mesmo que não tenham postado réplicas. $O$ recurso de inclusão de comentário em trechos específicos do texto e a inclusão de respostas, para os demais usuários, podem ter estimulado a continuidade da participação nas discussões.

\subsection{Desengajamento}

De maneira geral foi possível perceber, pela observação das atividades, que ocorrera um desinteresse em fazer parte da comunidade. Isso, pois a maioria dos usuários que participaram das discussões não se tornaram membros da comunidade Participação Social. Verificou-se que dentre essas pessoas, há aqueles que perfil pessoal não está mais disponível para visualização, dando a entender que esse foi excluído por seu dono - provavelmente após o término das discussões.

Ainda que esta fase também esteja relacionada com os recursos de todos os blocos funcionais mencionados, pois esses podem apresentar erros de funcionamento ou problemas de entendimento pelo usuário; o desengajamento se mostrou mais atrelado ao comportamento observado na comunidade do que na utilização de suas funcionalidades. Vê-se pelo atributo desafio, por exemplo, que não foram apresentadas atividades complexas ou recursos de difícil uso, a ponto desestimular seus usuários.

O efeito positivo provocado nos participantes pode não ter sido suficiente para tornar o engajamento um estado quase que permanente. Apesar das trocas terem ocorrido entre os usuários, muitas das indagações ficaram abertas e nem todos os participantes tiveram vontade de prosseguir a discussão no momento em que pontos de vista diferentes eram colocados. A mediação não esteve tão presente e, mais do que isso, houve um intervalo entre o término das contribuições até a publicação dos textos deliberados, sem novas comunicações; o que pode ter causado uma impressão de descompromisso da parte das organizações públicas envolvidas. Ressalta-se, por exemplo, que apenas duas pessoas, que participaram das duas primeiras discussões, retornaram para participar da terceira. Esta falta de comunicação pode ter sido a causa de efeito negativo sobre alguns dos usuários.

Ruídos e interrupções externas, que poderiam atrapalhar a concentração dos usuários, não demonstraram ter influenciado o desengajamento. Verificou-se que a maioria dos usuários tinha uma faixa horária padrão para participar das discussões. Provavelmente se tratava de um horário livre no qual poderiam participar das atividades da comunidade sem interrupções.

$\mathrm{O}$ atributo tempo perdido se refere à consciência de que se gastou muito mais tempo do que o esperado em alguma atividade. Nesse sentido, apenas um dos participantes pode ter perdido esta noção, enquanto fazia suas contribuições, pois ele iniciou as postagens de comentário por volta das $23 \mathrm{hs}$ e quando acabou eram quase $2 \mathrm{hs}$ do dia seguinte. Este usuário se tornou um dos membros da comunidade e participou das duas primeiras discussões. Ainda assim, esse atributo não se mostrou tão relevante nessa fase, a partir da análise das interações.
A respeito do atributo usabilidade não foi possível avaliar, apenas por meio das interações, se as pessoas tiveram alguma dificuldade em utilizar os recursos da plataforma, de maneira a desistirem de continuar a participar das discussões. Viu-se que em alguns comentários, por exemplo, havia reclamações de alguns recursos, principalmente da impossibilidade de inserir um novo comentário direcionado a um dos trechos do texto. Neste caso, parecia que o recurso em si que estava com problema e não que os usuários o estivessem usando incorretamente.

Verificou-se que não se explorou tanto os indicadores "curti" (concordância/aprovação) e "não curti" (discordância/ reprovação), presentes em todos os conteúdos postados. É provável que tenham entendido a sua função, mas não viram a necessidade ou a importância em explorá-lo como referência sobre um comentário.

\section{CONCLUSÃO}

A maior parte dos comentários entre os participantes, nas discussões, expunha uma opinião de concordância/discordância sobre um determinado trecho do texto em consulta ou sobre alguma fala dos membros representantes da videoconferência, com e sem argumentação. Isso mostrou que os participantes estiveram mais envolvidos na exposição e negociação de conceitos. Esse comportamento pode evidenciar uma menor intensidade de engajamento, sob o ponto de vista do debate desenvolvido, considerando a finalidade de desenvolvimento de novos conhecimentos [16].

Foi possível verificar de que maneira os participantes passaram pelo processo de engajamento, ainda que, na maioria dos casos, o período de engajamento tenha se restrito ao dia em que inseriram suas contribuições. $\mathrm{O}$ atributo feedback foi limitado aos e para os participantes, deixando muitas questões em aberto. Contudo a experiência, apesar de positiva no geral, não os cativou o suficiente para que se mantivessem engajados por mais tempo.

As funcionalidades dos blocos que compõem a plataforma são passíveis de melhoria, mas de maneira geral oferecem recursos interessantes para a utilização dos usuários. Entretanto, parte desses recursos não foi bem explorado, como foi o caso da construção da identidade pessoal, porque as pessoas pouco desenvolveram seus perfis. $O$ conjunto de funcionalidades considerado como o mais importante referiu-se aos recursos que possibilitavam o debate entre os participantes nas consultas.

O debate, então, pode ter sido um dos estimuladores ao engajamento do usuário, sobretudo quando eram postadas respostas. Contudo, a menor extensão das conversas e a pouca incidência de usuários retornando para replicar o que tivessem comentado sobre de suas contribuições, deixa evidente que os participantes não costumavam voltar à plataforma pelo estímulo que estas conversas provocavam.

Isso também é sugerido pelo estudo [18] que avalia que a nova audiência nas mídias sociais está mais receptiva e ansiosa por participar. Contudo, se a abordagem continua sendo como a forma tradicional, proporcionando as mesmas experiências do "mundo real", esta audiência pode não se engajar. Desse modo, o debate sobre o conceito de engajamento promovido por mídias sociais não pode ser limitado ao uso de ferramentas que possibilitam o compartilhamento de informações. Este deve ser abordado em um contexto de transformação social e cultural [17]. 
O recurso de compartilhamento de informações, disponível na página pessoal do usuário - chamado mural; acabou por não ser utilizado pela maioria dos membros e pelos participantes da comunidade. Em contrapartida, não era possível determinar a presença de um usuário, que estivesse acessando a plataforma. De qualquer modo não foram oferecidos recursos de troca de mensagens, como um chat; neste ambiente.

Durante a primeira e a segunda discussão, um dos usuários pediu/sugeriu aos administradores um recurso de votação, para que fosse possível atribuir valor a determinados comentários. A quantidade de votos serviria para indicar o quão importante ou polêmico era o assunto abordado naquele ponto, merecendo uma maior atenção no momento em que as informações fossem agregadas ao texto oficial. Ainda que sem o recurso, sugeriu-se incluir estes votos no texto do comentário. Neste momento não se pensou em utilizar os indicadores "curti" e "não curti", que não se mostraram menos importantes durante os debates.

O retorno desses usuários, ou o seu reengajamento, foi a fase que ficou menos perceptível, diante da verificação de que parte dos usuários não retornou para participar da terceira discussão e nem se tornou membro da comunidade. Desse modo, pode-se presumir que os usuários se sentiram motivados a estar na consulta e que durante a sua ocorrência, estiveram concentrados. No entanto, após o término da primeira e da segunda discussão, não tiveram mais fortes motivos para retornar, sob seus pontos de vista.

Viu-se que a mídia social tem o seu papel na promoção do engajamento de seus usuários, ao oferecer condições para captação das contribuições, mecanismos de divulgação das informações, recursos para a criação de comunidades, oportunidades de desenvolvimento de redes de contatos, além de abarcar algumas dinâmicas capazes de engajar seus usuários. Contudo, estas capacidades perdem o seu sentido, quando não são incorporadas rotinas de monitoramento/acompanhamento, estabelecidas regras e regulamentos para uso dos dados, bem como o estímulo às informações e processos de agregação transparentes.

Na tentativa de contribuir para uma melhor experiência de uso do usuário, poderiam ser consideradas algumas sugestões sobre as funcionalidades da plataforma. Estas foram levantadas na observação das interações e também informadas pelos entrevistados. Assim, têm-se para:

\section{Blocos Conversação e Compartilhamento}

- Bloqueio da edição de comentários pelos usuários que os postaram, após o término do prazo da consulta;

- Bloqueio da inserção de comentários, após o término do prazo consulta;

- Monitoramento dos questionamentos dos usuários, quando voltados aos conteúdos, mesmo após dias de sua publicação;

- Revisão da inserção de um novo comentário, pois este falhou na primeira discussão;

- Revisão dos contadores de comentários por trecho de texto, pois alguns estavam contando a mais ou a menos.

Blocos Reputação e Grupo
- Disponibilização de indicadores de importância (ou recursos de votação) nos trechos de texto disponíveis para deliberação e nos comentários postados;

- Disponibilização de um recurso de avaliação que pudesse ser usado para identificação de membros influentes nas comunidades;

- Disponibilização de um recurso em que um usuário pudesse ter seu papel identificado dentro das comunidades em que fizesse parte;

- Possibilidade de inserção de passos informativos para deixar mais transparente as atividades da comunidade, desde seu início, até a sua concretização em política ou ações.

\section{Blocos Identidade, Relacionamento e Presença}

- Maior regulamentação da política de uso dos dados inseridos na plataforma, sobretudo para os dados pessoais;

- Disponibilização de um recurso para importação de dados pessoais de contas externas, como de outras mídias sociais, para automatizar o preenchimento do perfil da plataforma;

- Integração da plataforma com outras mídias sociais externas. De modo que o conteúdo postado no mural de um usuário, na plataforma, possa ser repostado automaticamente em sua conta de Facebook, por exemplo;

- Fornecimento de indicadores que informem se os usuários estão online ou off-line no momento, se fossem disponibilizados chats internos.

Por fim, ressalta-se que há interesse na expansão e melhoria da plataforma. Mas a falta da promoção de engajamento em seus usuários pode prejudicar este processo. Deve-se lembrar de que este engajamento possui duas perspectivas: a experiência de uso do usuário, perante o sistema com o qual interage, e as oportunidades de envolvimento oferecidas nas atividades propostas pelas organizações ou entidades públicas nas comunidades. Deve existir um equilíbrio entre estas perspectivas, para que os usuários se sintam motivados a participar.

\section{AGRADECIMENTOS}

Agradecemos à Secretaria Geral da Presidência da República, sobretudo aos administradores do portal Participa.br.

\section{REFERÊNCIAS}

[1] Mergel, I. 2012. The social media innovation challenge in the public sector. Information Policy, 17, 3-4, 281-292.

[2] Zhang, W., Johnson, T. J., Seltzer, T. e Bichard, S. L. 2010. The revolution will be networked: the influence of social networking sites on political attitudes and behavior. Social Science Computer Review, 28, 1, 75-92.

[3] Attfield, S., Kazai, G., Lalmas, M. e Piwowarski, B. 2011. Towards a science of user engagement. In Proceedings of the 4th ACM International Conference on Web Search and Data Mining [Position paper] (Fev. 2011).

[4] Criado, J. I., Sandoval-Almazan, R. e Gil-Garcia, J. R. 2013. Government information though social media. Government Information Quarterly, 30, 319-326. 
[5] Kietzmann, J.H., Hermkens, K., McCarthy, I.P. e Silvestre, B.S. 2011. Social media? Get serious! Understanding the functional building blocks of social media. Business Horizons, 54, 241-251.

[6] O'Brien, H. L. e Toms, E. G. 2008. What is User Engagement? A conceptual framework for defining user engagement with technology. Journal of the American Society for Information Science \& Technology, 59, 6, 938955.

[7] McCarthy, J. e Wright, P. 2004. Technology as experience. Cambridge, Massachusetts: MIT Press.

[8] Maanen, J. V. 1979. Reclaiming qualitative methods for organizational research: a preface. Administrative Science Quarterly, 24, 4 (Dez. 1979), 520-526.

[9] Gil, A. C. 2002. Como elaborar projetos de pesquisa. 4. ed. São Paulo: Atlas.

[10] Kozinets, R. V. 2010. Netnography: doing ethnographic research online. Thousand Oaks, CA: Sage Publications.

[11] Hine, C. 2000. Virtual Ethnography. Londres: Sage.

[12] Brasil. 2014. Decreto no 8243, de 23 de maio de 2014. Institui a Política Nacional de Participação Social - PNPS e o Sistema Nacional de Participação Social - SNPS, e dá outras providências. Diário Oficial da União, Brasília, DF, 26 mai. 2014, Seção 1. Disponível em: <http://www.planalto.gov.br/ccivil_03/_Ato20112014/2014/Decreto/D8243.htm>. Acesso em: 26 jan. 2015.

[13] Machado, G. 2014. Secretaria Geral da Presidência da República (Org.). Compromisso Nacional de Participação Social (CNPS) \& Passo a passo à adesão ao compromisso. Participa.br. Disponível em: 〈http://www.participa.br/participacaosocial/compromisso>. Acesso em: 26 jan. 2015.
[14] Banks, A. 2014. comScore (Ed.). Brasil Digital Future in Focus 2014. Disponível em:

<http://www.comscore.com/por/Insights/Presentations-andWhitepapers/2014/2014-Brazil-Digital-Future-in-FocusWebinar>. Acesso em: 24 out. 2014.

[15] Gunawardena, C. N.; Lowe, C. A. e Anderson, T. 1997. Analysis of a global online debate and the development of an interaction analysis model for examining social construction of knowledge in computer conferencing. Journal of Educational Computing Research, 17, 4, 397431.

[16] Costa, A. C. da S. 2014. Analytics do Participa.br: março de 2014. Disponível em: <http://www.Participa.br/articles/public/0006/7310/Analytic s_Participa_março_2014.pdf>. Acesso em: 22 jul. 2014.

[17] Panagiotopoulos, P. 2012. Towards unions 2.0: rethinking the audience of social media engagement. New Technology, Work and Employment, 27, 3, 178-192.

[18] Participa. 2014. Secretaria Geral da Presidência da República (Org.). Página Inicial. Brasília. Disponível em: <www.participa.br>. Acesso em: 24 out. 2014.

[19] Participa. 2014. Secretaria Geral da Presidência da República (Org.). Comunidade Participação Social. Brasília. Disponível em: <www.participa.br/participacaosocial>. Acesso em: 24 out. 2014.

[20] Machado, G. 2014. Secretaria Geral da Presidência da República (Org.). Quem somos? Participa.br. Disponível em: 〈http://www.Participa.br/ajuda/ajuda/quem-somos>. Acesso em: 29 jul. 2014. 